\title{
Distribuição temporal e espacial da umidade do solo em sistemas de irrigação por gotejamento subsuperficial
}

\author{
Junior Kunz', Viviane Schons de Ávila², Mirta Petry³ \\ ' Mestrando pelo Programa de Pós Graduação em Ciência do Solo - Universidade Federal de Santa Maria - UFSM \\ ${ }^{2}$ Mestranda pelo Programa de Pós Graduação em Engenharia Agrícola-- Universidade Federal de Santa Maria - UFSM \\ ${ }^{3}$ Doutorado em Ciência do Solo (UFSM) -Professor Adjunto I do curso de Agronomia, na área de Engenharia de Água e Solo - \\ Universidade Federal de Santa Maria - UFSM
}

\section{RESUMO}

A água é um recurso natural que está cada vez mais escasso. Considerando o uso total da água, a agricultura utiliza aproximadamente $70 \%$ e, assim, percebe-se que este é o fator essencial para a produção agrícola, estando fortemente relacionada com as variações de produtividade. A irrigação surge como uma estratégia para incrementar a produtividade, fornecendo água às plantas em intervalos de tempos regulares, conforme sua necessidade. Visando o melhor gerenciamento dos recursos hídricos, observa-se um variado conjunto de tecnologias para a irrigação, dentre eles a irrigação subsuperficial, que é um tipo de gotejamento. A irrigação por gotejamento apresenta uma elevada eficiência se comparada a outros métodos, pois proporciona um melhor uso da água, ou seja, menor desperdício. Porém, a principal carência deste sistema é monitorar a distribuição da água no perfil do solo, além da ausência de informações condizentes sobre o caudal a ser aplicado em cada irrigação. Este trabalho tem como objetivo estudar a distribuição espacial e temporal da água no perfil de um solo franco-arenoso, submetido a um sistema de irrigação por gotejamento subsuperficial.

Palavras-chave: irrigação subsuperficial; eficiência de irrigação; gotejamento; bulbo úmido; modelagem matemática; sensores FDR.

\begin{abstract}
Water is a natural resource which is increasingly scarce. Of total water use, agriculture uses about $70 \%$, so you realize that this is the essential factor for agricultural production, being strongly associated with productivity changes. Irrigation emerges as a strategy to improve productivity, providing water to plants in regular intervals of time as per your need. To better management of water resources, there is a wide range of technologies for irrigation, among these subsurface irrigation. Drip irrigation has a high efficiency compared to other methods, it provides a better use of water. But the main deficiency of this system is to monitor the distribution of water in the soil profile, besides the lack of consistent information flow to be applied at each irrigation. The objective of this work was to study the spatial and temporal distribution of water on a sandy loam soil of a system of subsurface drip irrigation profile.
\end{abstract}

Key words: subsurface irrigation; irrigation efficiency; drip; wet bulb; mathematical modeling; FDR sensors. 


\section{INTRODUÇÃO}

A água é um recurso natural indispensável à vida de todos os seres vivos e é parte importante da composição de tudo que existe na natureza. De acordo com Paz et al. (2000), o Brasil é considerado um país privilegiado no que diz respeito a recursos hídricos, concentrando $18 \%$ do potencial de água do planeta, além de contar com a água subterrânea com boa parte de seu potencial ainda não explorado, mas que apresenta um custo muito elevado para ser explorada. Porém, a escassez de água já é realidade em alguns locais, seja pela falta de água em si ou pela contaminação dos mananciais, e encontra-se cada vez mais limitada devido às ações impactantes do homem sobre as fontes ainda existentes, e seu uso indiscriminado (ANGELO et al., 2000).

No Brasil, quase metade da água consumida destina-se a agricultura irrigada (CARDOSO, et al, 1998), sendo portanto, elemento essencial ao desenvolvimento da agricultura. Segundo Paz et al. (2000), o Brasil apresenta um grande potencial para a agricultura irrigada, com cerca de $5 \%$ da área cultivada irrigada (aproximadamente 4,6 milhões de hectares, sendo que o potencial de irrigação chega a 35 milhões de hectares). Porém, esse mesmo autor relata que essa pequena parcela é responsável por apenas $16 \%$ da produção total e por $35 \%$ do valor da mesma. Isso demonstra uma larga margem para ampliação da área irrigada, considerando os recursos hídricos e o potencial dos solos existentes no Brasil.

De acordo com Ferreira (2011), a irrigação é um método artificial pelo qual se calcula a quantidade de água aplicada na planta, com o objetivo de suprir as necessidades hídricas na falta de chuva e, além disso, segundo Howell (2000), é um recurso tecnológico fundamental para que a produção de alimentos e fibras ocorra em escala suficiente, a fim de suprir as necessidades de uma população mundial que cresce continuamente. A irrigação pode ser encontrada na maioria das áreas agrícolas tecnificadas, pois esta técnica se traduz em maiores produtividades, melhor qualidade do produto e independência do fator precipitação, proporcionando às culturas um crescimento produtivo verticalizado (DALRI, 2002).

Tendo em vista a escassez dos recursos hídricos em muitos países, Zegbe et al. (2006) indicam a necessidade de adotar estratégias de irrigação que melhorem a eficiência de uso da água. Atualmente, existem diversos tipos de irrigação, os quais podem ser escolhidos de acordo com o relevo da região, tipo de cultura e eficiência desejada. Os métodos mais utilizados são irrigação por aspersão mecanizada (pivô central), irrigação por sulcos e irrigação localizada.

Pode-se usar a irrigação localizada tanto na superfície do solo, quanto enterrada, recebendo neste caso o nome de irrigação por gotejamento subsuperficial. Segundo Phene e Ruskin (1995), a irrigação por gotejamento subsuperficial aperfeiçoa a eficiência de aplicação, pois o volume de água armazenado pode ser maior do que nos outros sistemas de irrigação.

Porém, existe uma lacuna no estudo deste tipo de irrigação, que se refere à observação de como a distribuição da água no perfil do solo é afetada pelas propriedades insaturadas do solo. Além disso, a literatura mostra poucos estudos relacionados ao efeito de diferentes profundidades e espaçamento de linhas laterais em gotejo subsuperficial, assim como o modo como a água distribui-se na zona das raízes de plantas $(0-10 \mathrm{~cm})$. Este volume de solo molhado é conhecido por bulbo molhado e esta região é de extrema importância, pois é dela que as raízes das plantas absorvem água e nutrientes (PATEL, 2008).

$\mathrm{O}$ uso da tecnologia de irrigação subsuperficial requer a otimização dos parâmetros operacionais, tais como a frequência e a duração da irrigação, o tipo do emissor de descarga, o espaçamento e o local de instalação das laterais de gotejamento (SKAGGS et al., 2004). Assim, torna-se fundamental o conhecimento da distribuição exata de água em torno dos emissores, a fim de fornecer uma ótima distribuição na zona da raiz das culturas e evitar a ocorrência de molhagem excessiva na superfície do solo e percolação no perfil do solo.

Desta forma, objetivo deste trabalho é estudar a dinâmica da água no perfil do solo e formação do bulbo úmido em um sistema de irrigação por gotejamento subsuperficial. Além disso, será discutida uma possível forma de aferição da distribuição da água no solo, através da utilização do método de frequência de domínio de tempo, com sensores FDR. 


\section{REVISÃO DE LITERATURA}

Existem vários fatores que, por muitas vezes, dificultam a produção agrícola no Brasil e no mundo. A irrigação surge como uma ferramenta essencial para enfrentar alguns desses problemas, como a falta de chuvas e a má distribuição das mesmas em alguns locais, sendo esta, a principal responsável pela frustração de safras no Rio Grande do Sul.

As instabilidades climáticas estão presentes em quase todas as regiões do Brasil, com períodos de déficit hídrico e, em contrapartida, períodos de umidade excessiva (JADOSKI et al., 2003). Essas instabilidades provocam oscilações na produtividade agrícola do país, tendo em vista que a maioria das culturas apresenta períodos críticos com relação à necessidade hídrica, e o suprimento inadequado de água pode reduzir drasticamente a produção e causar problemas no desenvolvimento das plantas.

Outro fator que também desafia a agricultura é a necessidade de produção de alimentos nos próximos anos, pois as taxas de crescimento da produção agrícola mundial, superadas pelas dos incrementos populacionais nos últimos anos, vêm causando certa intranquilidade com relação à segurança alimentar. Para aumentar a produção de alimentos, a produção agrícola mediante a irrigação, surge como uma ótima alternativa a nível mundial, pois tem possibilitado um número maior de safras por ano. E, além disso, como o setor agrícola é o maior consumidor de água, a irrigação surge como estratégia ao desenvolvimento sustentável da agricultura, de forma que o controle e a administração adequados e confiáveis possibilitarão o manejo justo e equilibrado, preservando a sua qualidade (PAZ, et al., 2000).

Apesar de ser uma técnica antiga, a irrigação vem sendo útil para aumentar a produtividade das culturas em geral. O uso da irrigação diminui o risco dos agricultores no que se refere às produções a serem alcançadas (SILVA, FARIA e REIS, 2003) e à dependência das chuvas. É uma tecnologia que requer investimentos representativos e está associada à utilização intensiva de insumos, tornando importante a análise econômica dos componentes envolvidos no sistema.

Um bom sistema de irrigação deve aplicar água no solo uniformemente, até determinada profundidade, proporcionando a umidade necessária ao desenvolvimento vegetal (DRUMOND, 2013).

Atualmente, existem vários tipos de irrigação, que podem ser escolhidos de acordo com o relevo do local, o tipo de cultura, o nível de investimento, entre outros fatores, sendo os principais deles: irrigação por aspersão mecanizada, irrigação por superfície e irrigação localizada. Dentro desta última está a irrigação subsuperficial, que é nosso foco de estudo.

\section{Irrigação Localizada - Gotejamento}

No Brasil, a irrigação localizada representa $8 \%$ do total das áreas irrigadas (PAULINO et al., 2011), o que corresponde a, aproximadamente, 337 mil hectares (CARVALHO, 2004). Segundo Christofidis (2006), a área irrigada pelos métodos localizados mais do que triplicou no período de 1996 a 2003.

A irrigação localizada caracteriza-se por aplicar a água de maneira localizada, de forma a umedecer volumes restritos de solo no entorno das plantas. Isso reduz as perdas de água por evaporação, permitindo elevados índices de eficiência de irrigação e, além disso, as pressões utilizadas no sistema são bastante baixas, entre 0,6 a 3,5 bar $(6-35 \mathrm{mca})$, o que reduz significativamente a demanda de energia (FILHO, 2011). Nesse sistema, o solo da região radicular tem sua umidade mantida próxima à capacidade de campo, o que é conhecido como bulbo molhado, e é dele que as raízes das plantas retiram água e nutrientes, podendo atingir, facilmente, uma eficiência de aplicação de 90\% (WU e GITLIN, 1983).

De acordo com Bernardo et al. (2008), a água é aplicada em pequenas intensidades (1 a 160 litros por hora), porém com alta frequência (turno de rega de um a quatro dias), e para isso, a aplicação da água é feita por meio de tubos perfurados com orifícios de diâmetros reduzidos ou 
por meio de gotejadores e microaspersores denominados emissores, dos mais diferentes tipos, modelos e características. Estes gotejadores poderão estar colocados diretamente à linha de derivação, onde a mesma é aparente, ou ligada por microtubo e adaptador, sendo que, neste caso, apenas os gotejadores são visíveis, ou em outros casos em subsuperfície, em profundidade no perfil do solo onde não observa-se visualmente nenhum gotejo e nem linha de irrigação.

Uma das principais dificuldades deste tipo de sistema é a determinação do número de emissores que devem ser utilizados para se atingir a porcentagem de área a ser molhada por planta, sendo necessário determinar as dimensões do bulbo molhado para cada um dos emissores utilizados (SOUZA et al., 2006) mantendo a sobreposição necessária para que se atendam as necessidades hídricas da cultura e, obtendo-se assim, um dimensionamento mais racional e econômico, do ponto de vista de consumo de água e de custo de implantação do sistema (AZEVEDO, 2008).

Conforme o tipo de solo, o movimento da água assume uma determinada forma (Figura 1), existindo uma relação entre o raio de umedecimento (dimensão horizontal) e a profundidade de umedecimento (dimensão vertical). Essas dimensões determinam o bulbo úmido.

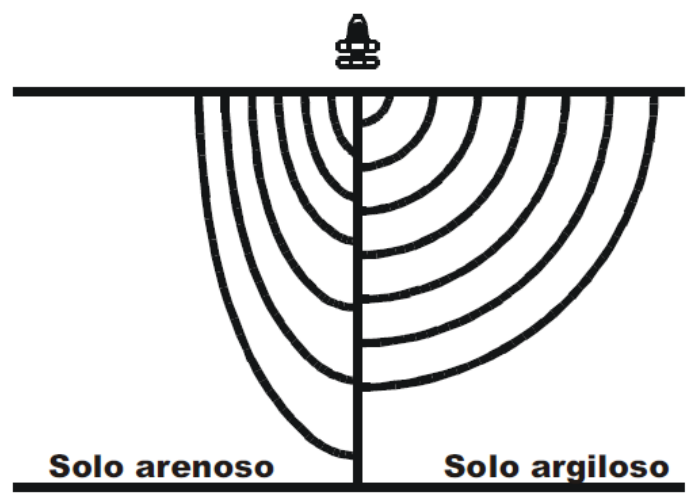

Figura 1- Distribuição de água de um gotejador

Segundo Reinert et al. (2001), a textura e a estrutura são características que influenciam expressivamente a movimentação da água no solo, uma vez que determinam a quantidade de macroporos presentes em seu perfil, os quais são de extrema importância na condutividade hidráulica do solo. Outras características do solo que também interferem expressivamente na infiltração da água são: a forma dos poros e a sua continuidade. Solos de textura grossa, ou seja, arenosos, possuem maior quantidade de macroporos que os de textura fina (argilosos) e, conseqüentemente, apresentam maior condutividade hidráulica e taxa de infiltração.

Entre as principais vantagens deste tipo de irrigação estão: a maior eficiência do uso da água, maior produtividade, maior eficiência na adubação, maior eficiência no controle fitossanitário, não interfere nas práticas culturais, adapta-se aos diferentes tipos de solos e topografia, pode ser praticado com água salina ou em solos salinos e, uma vez instalado, necessita pouca mão de obra (BERNARDO, 2008).

Por outro lado, as desvantagens desse sistema são os entupimentos dos orifícios, a distribuição do sistema radicular, coeficiente de variação de fabricação, expoente de descarga do gotejador, sensibilidade do gotejador à variação da temperatura e de pressão, entre outros (SOLOMON, 1985).

\section{Gotejamento Subsuperficial}

O sistema de irrigação localizada por gotejamento subsuperficial caracteriza-se por aplicar a água diretamente na raiz da planta, com pequenos volumes aplicados e alta frequência de aplicação, com auxílio das forças capilares (TESTEZLAF, 2002). Segundo Mosca, Testezlaf e Gomes (2005), este sistema representa significativa evolução no processo da aplicação de água às culturas e, além disso, é uma resposta para a necessidade de se procurar novos sistemas de 
irrigação, mais eficientes, que reduzam o consumo dos recursos hídricos, seu custo de instalação e, sobretudo, que minimizem os problemas de escassez de água.

No Brasil, a irrigação por gotejamento subsuperficial iniciou-se em 1996, em São Paulo (AGUIAR, 2002) e constitui-se de um método moderno de irrigação, permitindo a aplicação de pequenas quantidades de água com os gotejadores localizados abaixo da superfície do solo, com as taxas de descarga em intervalos semelhantes às usadas na irrigação superficial, usado para fornecer água as plantas, mantendo a superfície do solo seca, o que garante a água disponível apenas para a região radicular das plantas. Os gotejadores estão dispostos abaixo da superfície do solo, a fim de conservar a água, controlar ervas daninhas, reduzir a evaporação e aumentar a longevidade dos gotejos laterais (PATEL, 2008).

Esse sistema de irrigação utiliza gotejadores autocompensantes, inseridos em tubulações, as quais são enterradas a uma determinada profundidade, que pode variar com os tipos de solo e cultura (NOGUEIRA et al., 1997).

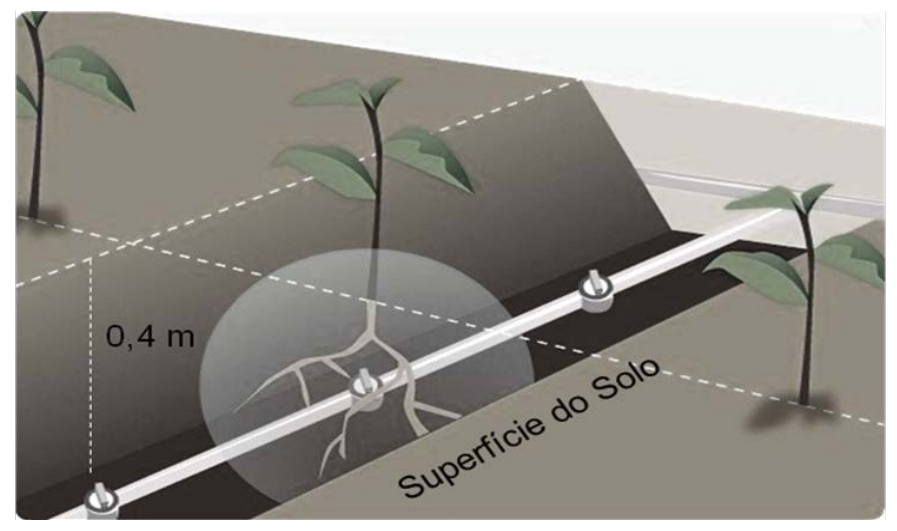

Figura 2- Distribuição de água de um gotejador subsuperficial

Ainda de acordo com o mesmo autor, os componentes de um sistema de irrigação por gotejamento subsuperficial são: sistema de bombeamento, tubulação adutora, cabeçal de controle, tubulação principal, setores e subsetores de irrigação, ventosas de duplo efeito e coletores de limpeza. Além disso, as características necessárias a um gotejador são: resistência ao desgaste, capacidade de autocompensação de pressões, capacidade de autolimpeza, possibilidade de fácil colocação e retirada, e tamanho reduzido.

Segundo Phene et al. (1987) este sistema apresenta cinco vantagens com relação ao gotejamento superficial: i) aumento da vida útil do sistema juntamente a uma menor mão de obra anualmente empregada; ii) como a superfície do solo fica geralmente seca, ocorre a redução de doenças bem como do controle da infestação de ervas daninhas; iii) com o solo seco entre as linhas de cultivo, aumenta a trafegabilidade e reduz a compactação do solo; iv) água e nutrientes são usados com mais eficiência; e v) há uma significativa melhora nos rendimentos, bem como em algumas qualidades da produção. Além, disso, outra grande vantagem deste sistema é a redução do escoamento superficial (BAR-YOSEF et al., 1989; ORON et al., 1991).

Por outro lado, Testezlaf (2002) cita como desvantagens: i) o custo inicial é elevado; ii) perfil de molhamento da água não pode ser visualizado; iii) suscetível a entupimento de emissores por intrusão de raízes; iv) necessita maior controle da irrigação como uso de hidrômetros, válvulas de drenagem e antivácuo. Além disso, outras desvantagens do sistema são o potencial acúmulo de sais na região do perfil acima da linha lateral e abaixo da superfície do solo, reduzido movimento vertical ascendente de água em solos arenosos e o conhecimento ainda escasso sobre o sistema como um todo (EMBRAPA, 1997).

Outra grande limitação deste sistema geralmente é relacionada ao estabelecimento inicial da cultura, pois por não umedecer a superfície do solo, o sistema não proporciona condições satisfatórias de umidade para a germinação de sementes ou "pegamento" de mudas. Portanto, é 
necessário o uso de um segundo sistema de irrigação na fase inicial, frequentemente por aspersão, o que aumenta os custos e reduz o retorno econômico (PAVERO, 2002; GUSHIKEN, 1995).

A determinação da profundidade de instalação e espaçamento dos gotejadores depende das dimensões do bulbo úmido e da distribuição da umidade no solo, a fim de que se torne possível uma ótima distribuição de água na zona radicular das plantas (ROMERO et al., 2004).

\section{Formação do bulbo úmido}

O bulbo úmido pode ser definido como a forma do volume de solo umedecido, proveniente de uma fonte pontual de água no solo, o qual depende do equilíbrio entre as forças capilares e gravitacionais, assim como da textura do solo, da condutividade hidráulica, da vazão do gotejador, do conteúdo inicial de água no solo (KELLER, 1984) e do total de água aplicado no solo (SCHWARTZMAN e ZUR, 1985).

De acordo com Souza et al. (2006), uma das maiores dificuldades encontradas no planejamento deste sistema é a determinação do numero de emissores que devem ser utilizados para se atingir a área molhada desejada, sendo necessário determinar as dimensões do bulbo molhado para cada um dos emissores utilizados, no caso, o espaçamento entre emissores e entre as linhas laterais.

O conhecimento da forma e dimensão do bulbo molhado pode evitar perdas de água por lixiviação e superposição exagerada dos emissores. Além disso, permite definir aspectos importantes, como lâmina e frequência de irrigação, número de gotejadores, dimensionamento hidráulico (COOK et al., 2006) e o próprio manejo da irrigação (HAO et al., 2007).

Conforme relatam Li et al. (2004), em solos de textura muito argilosa, o máximo diâmetro molhado ocorre na superfície, e por outro lado, em solos de textura arenosa, o máximo diâmetro molhado ocorre mais profundamente. O movimento do ar e da água no solo ocorre através dos macroporos, enquanto que, nos microporos, o movimento do ar é dificultado, e o da água fica restrito principalmente a capilaridade (HILLEL, 1980). Dessa forma, apesar dos solos arenosos apresentarem reduzida porosidade total, os movimentos do ar e da água são rápidos nesses solos, em função da predominância de macroporos. Já nos solos de textura fina, apesar de apresentarem grande espaço poroso, os movimentos dos gases e da água são relativamente lentos, devido a presença predominante de microporos.

Li et al. (2004) também apresentaram uma equação empírica para o cálculo de largura e profundidade de bulbo molhado para emissores de vazão entre 0,5 a $7,81 \mathrm{~h}^{-1}$ :

$$
d=0,76 z^{0,20}\left(\frac{K_{s}}{q}\right)^{-0,05}
$$

Em que:

d: diâmetro molhado medido no ponto mais largo (m);

$\mathrm{z}$ : profundidade molhada $(\mathrm{m})$;

q: vazão do emissor $\left(\mathrm{m}^{3} \cdot \mathrm{s}^{-1}\right)$;

$\mathrm{K}_{\mathrm{s}}$ : condutividade hidráulica do solo saturado $\left(\mathrm{m} \cdot \mathrm{s}^{-1}\right)$;

Schwartzman et al. (1986) também desenvolveram uma equação para estimar a dimensão do bulbo molhado, para emissores com vazão de 4 a $201 . h^{-1}$ :

$$
d=1,32 z^{0,35} q^{0,33} K_{s}^{-0,33}
$$

Em que:

d: diâmetro molhado medido no ponto mais largo (m); 
z: profundidade molhada $(\mathrm{m})$;

q: vazão do emissor $\left(\mathrm{m}^{3} \cdot \mathrm{s}^{-1}\right)$;

$\mathrm{K}_{\mathrm{s}}$ : condutividade hidráulica do solo saturado $\left(\mathrm{m} . \mathrm{s}^{-1}\right)$;

Segundo Keller e Bliesner (1990), o espaçamento entre emissores deve ser igual ou menor que $80 \%$ do máximo diâmetro molhado, para que se forme uma faixa contínua e uniformemente úmida, porém, conforme Benami e Ofen (1984), os melhores resultados sempre são obtidos com testes a campo.

O bulbo molhado pode ser medido diretamente no campo, com abertura de trincheiras ou de formas indiretas, através de modelos pré-estabelecidos. Mas devido à especificidade dos solos, ajustar os modelos para todos os solos nem sempre é uma estratégia adequada, tendo em vista os diversos tipos de solos que podem ser encontrados (BARROS et al., 2009).

\section{Condutividade Hidráulica}

Entre as propriedades físicas do solo, a condutividade hidráulica é uma das mais importantes quando se estudam fenômenos que, de alguma forma, estão ligados ao movimento da água no solo. A condutividade hidráulica $(K)$ é a capacidade que um solo possui de conduzir água através de seus poros, influenciado pela granulometria do solo, massa específica e viscosidade do fluido, as quais, por sua vez, são funções da temperatura e da pressão (PREVEDELLO, 1999). Ela é um parâmetro que representa a facilidade com que o solo transmite água (MESQUITA e MORAES, 2004).

O valor máximo de condutividade hidráulica é atingido quando o solo se encontra saturado, e é denominado de condutividade hidráulica saturada (REICHARDT, 1990), e através dela e de modelos matemáticos, pode-se determinar a condutividade hidráulica não saturada (K), a fim de obter informações sobre o movimento de água e solutos nos solos (MESQUITA e MORAES, 2004).

Em geral, o solo agrícola revela umidade inferior à saturação e, pela existência de uma função crescente entre condutividade hidráulica e volume, o valor daquela sob condição saturada é sempre inferior ao das condições não saturadas, para o mesmo solo. Além disso, a condutividade hidráulica do solo está entre as propriedades físicas do solo com a mais alta variabilidade (LIER e LIBARDI, 1999).

Segundo Prevedello (1999), para um solo não saturado, $K$ é função do conteúdo volumétrico de água no solo $(\theta)$, pois os poros ocupados pelo ar reduzem a área efetiva ao fluxo, aumentando a tortuosidade do fluxo remanescente. Assim, a condutividade hidráulica em meios porosos não saturados é menor do que nos saturados e é dependente do conteúdo de água. Miller e Low (1963) demonstraram que além do aumento da tortuosidade também ocorre uma alteração na viscosidade da água com a diminuição de $(\theta)$, dificultando seu fluxo.

O conhecimento da condutividade hidráulica não saturada é importante para qualquer estudo que envolva o movimento da água no solo, seja para estudar a própria dinâmica da água, seja para estudar o transporte de elementos químicos, nutrientes e defensivos agrícolas, bem como seus impactos potenciais ao ambiente, pois ela tem papel importante no suprimento hídrico à superfície do solo, para manutenção do processo de evaporação (MILLER e LOW, 1963).

Já a condutividade hidráulica saturada é determinada pela geometria, distribuição e continuidade dos poros, de forma que solos com maior número e melhor distribuição de tamanho de poros terá uma maior condutividade hidráulica. Esta porosidade vai depender da textura e estrutura do solo, e a sua densidade está suscetível ao manejo, que pode influenciar no movimento da água (MESQUITA e MORAES, 2004).

Essas propriedades hidráulicas do solo são parâmetros fundamentais para se compreender e modelar os processos de infiltração, evapotranspiração e transporte de solutos (ANGULOJARAMILLO et al., 2000), especialmente no caso do uso de sistemas de irrigação cujo emissor encontra-se em profundidade, a fim de que se torne possível prever a formação do bulbo úmido em diferentes profundidades e em diferentes tipos de solo. 
Existem várias propostas para se determinar a condutividade hidráulica e a curva de retenção de água no solo, pois são difíceis de serem determinados (DIRKSEN, 1999). Equações matemáticas foram utilizadas por Saxton et al. (1986) para determinar a condutividade hidráulica de um solo não saturado, através de modelos baseados na textura do solo e no potencial de água no solo, e concluíram que as mesmas podem ser utilizadas com a finalidade de calibração, de parâmetros obtidos tanto no campo quanto em laboratório.

\section{Modelagem da distribuição de água em subsuperfície}

Através da utilização de modelagem matemática pode-se representar o que acontece na natureza a partir de um modelo conceitual, com base em dados de observações do sistema real. Desta forma, pode-se compreender melhor o sistema e prever situações futuras, e a partir daí, direcionar as decisões.

Para a construção do modelo matemático que represente o sistema real são necessários: desenvolvimento do modelo conceitual, que envolve todo o levantamento e interpretação de dados e observações do sistema real; seleção do programa computacional a ser utilizado segundo as necessidades e os dados existentes; tradução do modelo conceitual para a linguagem matemática, construindo-se os diversos bancos de dados para a entrada das informações no programa selecionado; e calibração do modelo matemático construído de forma a diminuir as incertezas inerentes a uma representação simplificada (modelo matemático) de um sistema real, em geral, complexo (HASSUDA, 2000).

Dessa forma, o pacote de software HYDRUS-1D surge como uma importante ferramenta para observação do fluxo de água no solo em superfície, o qual pode ser utilizado para simular o fluxo de água e de solutos (bem como o calor e transporte de dióxido de carbono) em um meio variavelmente saturado, podendo compreender um fluxo vertical, horizontal ou em uma direção inclinada (SIMUNEK et al., 1998). Este programa resolve numericamente a equação de Richards para o fluxo saturado-insaturado de água e a dispersão de calor e transporte de solutos. O fluxo de água incorpora termos que explicam a absorção de água pelas raízes das plantas.

Esta ferramenta pode ser utilizada com a finalidade de simular processos como precipitação, irrigação, infiltração, evaporação, absorção de água pela raiz (transpiração), armazenamento de água no solo, ascensão capilar, drenagem profunda, recarga das águas subterrâneas. Além disso, através deste modelo também se pode avaliar o escoamento superficial quando o fluxo aplicado se torna maior do que a capacidade de infiltração de água no solo (SIMUNEK e HOPMANS, 2009).

Para observação do movimento da água em subsuperfície, acrescentaram-se novos parâmetros e atualizou-se para a versão Hydrus 2D/3D (SIMUNEK et al., 1999) que possibilita a simulação em três dimensões da dinâmica da água, a transferência de energia, o movimento de solutos e suas variáveis saturadas no solo. A dinâmica do fluxo se resolve pelo método de elementos finitos. O modelo matemático se baseia na equação de Richards:

$$
\frac{\partial \theta}{\partial t}=\left[\frac{\partial}{\partial x}\left(K(h)\left(\frac{\partial h}{\partial x}+1\right)\right)+\frac{\partial}{\partial z}\left(K(h)\left(\frac{\partial h}{\partial z}+1\right)\right)\right]-S
$$

Onde:

$\theta$ é o conteúdo volumétrico de água $\left(\mathrm{cm}^{3} \mathrm{~cm}^{-3}\right)$;

t é o tempo;

$\mathrm{z}$ é a profundidade $(\mathrm{cm})$;

h é o potencial hídrico do solo (tensão, em $\mathrm{cm}$ );

$\mathrm{S}$ é a quantidade de água absorvida pela planta $\left(\mathrm{cm}^{3} \mathrm{~cm}^{-3} \mathrm{t}^{-1}\right)$.

Este modelo possibilita a simulação do movimento da água em condições de uso da irrigação subsuperficial (SIMUNEK et al., 2008). 


\section{Sensores FDR (Frequency Domain Reflectometry)}

Existem diversos métodos para determinar o teor de umidade do solo, entre eles métodos diretos e indiretos. O método direto considerado padrão é o gravimétrico. Já os métodos indiretos determinam a umidade do solo a partir de outras propriedades, porém, a desvantagem deste método é a necessidade de calibrações locais, a fim de aumentar a precisão. Por outro lado, esses métodos indiretos são considerados ideais para monitoramento do teor de água no solo, pois são práticos, rápidos e acessíveis a repetições em um determinado ponto do perfil do solo (SILVA et al., 2008). Desta forma, estes métodos são considerados adequados para o monitoramento pontual de água no solo submetido ao sistema de irrigação subsuperficial.

Tais métodos são baseados nas propriedades dielétricas do solo e nas características de propagação de ondas eletromagnéticas (EM) no solo, que podem variar com o teor de água (volume) e salinidade (SKIERUCHA e WILCZEK, 2010). Um dos métodos mais utilizado é a frequência no domínio do tempo (FDR) ou técnica por capacitância, o qual tem sido utilizado na pesquisa, em função da sua precisão, facilidade de acoplamento a um sistema de coleta de dados, rapidez e segurança ao operador.

Através deste método, a determinação do conteúdo de água do solo é obtida pela estimativa da constante dielétrica calculada, e este valor é baseado no tempo de emissão/reflexão de um pulso eletromagnético, emitido por um gerador de pulsos, em hastes metálicas paralelas implantadas no solo, que servem como guia de ondas (PEREIRA et al., 2006).

Este método requer calibração cuidadosa, tanto durante a instalação quanto durante o tempo de uso, pois sua estabilidade, a longo prazo, é questionável, tendo em vista que a constante dielétrica é diretamente proporcional ao conteúdo de água e, no caso de solos arenosos, onde a água livre predomina, o sinal obtido não é linear com o conteúdo de água e é influenciado tanto pela quantidade, quanto pela temperatura do solo (ROQUE, 1996).

O equipamento de FDR utilizado na agricultura é basicamente composto por um testador de cabo, hastes condutoras (sonda de FDR), estas ligadas a um datalogger. Em caso de necessidade da leitura de diversas sondas, os dados podem ser adquiridos através de um multiplexador.

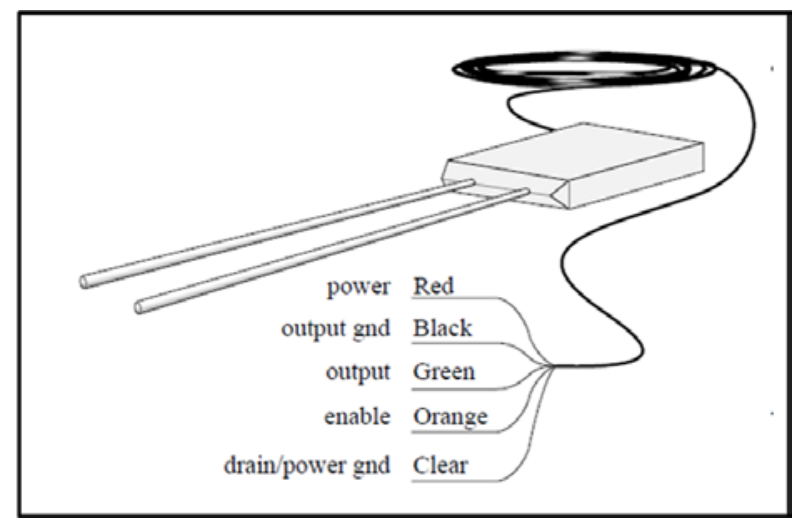

Figura 3- Refletômetro do conteúdo de água

\section{RESULTADOS ESPERADOS}

Sabe-se que o sistema de irrigação por gotejamento subsuperficial apresenta uma das mais altas eficiências, tendo em vista a aplicação de pequenas quantidades de água com os gotejadores localizados abaixo da superfície do solo, com as taxas de descarga em intervalos semelhantes as usadas na irrigação superficial. Este sistema também representa uma significativa evolução no processo da aplicação de água às culturas e, além disso, é uma resposta à necessidade de se procurar novos sistemas de irrigação, mais eficientes, que reduzam o consumo dos recursos hídricos, seu custo de instalação e, sobretudo, que minimizem os problemas de escassez de água, através de um uso de água racional e eficiente. 
Os problemas que envolvem a aplicação da água e o comportamento do fluxo de água em sistemas de irrigação por gotejamento subsuperficial necessitam ser mais bem estudados, a fim de servirem de subsídios para projetos de irrigação dessa natureza. A escolha entre a aplicação contínua ou intermitente de água na irrigação subsuperficial, assim como a escolha sobre o tipo de emissores a serem utilizados são fundamentais para o manejo desses sistemas, pois afetam a distribuição da água no sistema radicular. Por isso, monitorar minuciosamente o comportamento da frente de avanço e formação do bulbo molhado ajudará a técnicos e produtores irrigantes na tomada de decisão acerca do dimensionamento hidráulico e o manejo da irrigação de sistemas de irrigação dessa natureza.

A utilização de modelos de simulação do movimento da água no solo, a exemplo do Hydrus 2D/3D pode ser útil para explicar o comportamento da água em meios porosos, desde que sejam devidamente calibrados e validados, a partir de experimentos de campo. Da mesma forma, a aferição da distribuição da água através de sensores FDR também pode trazer resultados importantes com relação ao comportamento do fluxo de água no solo, tendo em vista que este método é adequado para este sistema de irrigação.

\section{REFERÊNCIAS}

AGUIAR, F. Gotejamento enterrado é novidade na irrigação da cana. Agrianual 2002, São Paulo,p.256-7, 2002.

ANDRADE, A. S.; DRUMOND, L. C. D. Adubação de pastagens irrigadas: princípios e recomendações. Revista Cerrado Agrociências, 2012. 1-18 p.

ANGELO, C. et al. A era falta d'água. Revista Superinteressante. Ed. Julho, 2000. Disponível em: < http://super.abril.com.br/ciencia/era-falta-d-agua-441456.shtml>

ANGULO-JARAMILLO, R.; Vandervaere, J.P.; Roulier, S.; Thony, J.L.; Gaudet, J.P.; Vauclin, M. Field Measurement of soil hydraulic properties by disc and ring infiltrometers: A review and recent developments. Soil \& Tillage Research, Madison, v.55, p.1-29, 2000.

AZEVEDO, L. P. de, Uso de dois espaçamentos entre gotejadores na mesma linha lateral e seus efeitos sobre a formação do bulbo molhado, produtividade e qualidade de Rabanete (Raphanus sativus L.). Tese apresentada à Faculdade de Ciências Agronômicas da UNESP Campus de Botucatu - SP, junho de 2008. Disponível em: < http://www.pg.fca.unesp.br/Teses/PDFs/Arq0326.pdf> Acesso em: 17 de novembro de 2013.

BARROS, A. C., FOLEGATTI, M. V., SOUZA, C. F., SANTORO, B. L. Distribuição de água no solo aplicado por gotejamento enterrado e superficial. Revista Brasileira de Engenharia Agrícola e Ambiental. Campina Grande, PB. v.13, n.6, p.700-707, 2009.

BAR-YOSEF, B.; SAGIV, B.; MARKOVITCH, T. Sweet corn response to surface and subsurface trickle phosphorus fertigation. Agronomy Journal, California, v.81, n.3, p.443-7, 1989.

BEN-GAL, A., LAZAROVITCH, N., SHANI, U., 2004. Subsurface drip irrigation in gravelfilled cavities. Vadose Zone J. 3, 1407-1413.

BENAMI, A.; OFEN, A. Irrigation engineering: sprinkler, trickle, surface irrigation, principles, design and agricultural practices. Haifa: IESP, 1984.

BERNARDO, S.; SOARES, A. A.; MANTOVANI, E. Manual de Irrigação. 8 ed. Viçosa: UFV, 2008. $625 \mathrm{p}$. 
CARDOSO, H.E.A.; MANTOVANI, E.C.; COSTA, L.C. As águas da agricultura. Agroanalysis. Instituto Brasileiro de Economia/Centro de Estudos Agrícolas. Rio de Janeiro. 1998. p.27-28.

CARLESSO, R.; PETRY, M. Pivot central: Parâmetros de operação e dimensionamento. Material apresentado em aula, Disciplia de Irrigação e Drenagem, Universidade Federal de Santa Maria - UFSM, maio de 2012.

CARVAlHO, D. F. de. Instituto de Tecnologia - Depto. de Engenharia. Material de aula. Universidade Federal Rural do Rio de Janeiro, 2004.

CHRISTOFIDIS, D. Situação das áreas irrigadas no Brasil. (Versão Preliminar). Brasília, DF: MMA/SRH, 1997. Não paginado. (Programa Nacional de Irrigação e Drenagem).

CHRISTOFIDIS, D. Água: Gênesis, Gênero e Sustentabilidade Alimentar no Brasil. Brasília, DF, UNB, PROÁGUA. Fev. 2006, 18p.

COOK, F. J. et al. Modelling trickle irrigation: comparison of analytical and numerical models for estimation of wetting front position with time. Environmental Modelling \& Software, v. 21, n. 9 , p. 1353-1359, 2006.

COSTA, R. N. T.; ARAÚJO, D. F. de, Irrigação por Superfície. Gestão Sustentável no Baixo Jaguaribe, Ceará. Fortaleza: Embrapa Agroindústria Tropical, p. 261-288, 2006. Disponível em: < http://www.gpeas.ufc.br/disc/sup/irrigacao_superficie.pdf> Acesso em: 15 de novembro de 2013.

DALRI, B. A. Efeito da frequencia de irrigação subsuperficial por gotejamento no desenvolvimento da cana-de-açucar (saccharum spp.). Irriga, Botucatu, v.7, n.1, 2002.

DASBERG, S.; OR, D. Drip Irrigation. Berlin: Springer, 162p, 1999.

DIRKSEN, C. Soil physical measurements. Reiskirchen: Catena Verlag. 1999.

DRUMOND, L. C. D. Irrigação de Pastagens. Universidade Federal de Viçosa, Campus do Rio Paranaíba, agosto 2013. Disponível em: < http://www.pecnordestefaec.org.br/2013/wpcontent/uploads/2013/08/Luis-C\%C3\%A9sar-Dias-Drumond-Irriga\%C3\%A7\%C3\%A3o-de-

Pastagem.pdf $>$ Acesso em 15 de novembro de 2013.

FERREIRA, V. M. Técnico Agropecuário: Irrigação e Drenagem. Ed. Floriano, 2001.

FILHO, P. S. Parâmetros físicos e hídricos relacionados com o avanço da frente de molhamento. 2011. 74 f. Tese (Doutorado em Engenharia Agrícola) - Universidade Federal de Santa Maria, Santa Maria, 2011.

GUSHIKEN, E.C. Irrigating with reclaimed water through permanent subsurface drip irrigation systems. In: INTERNATIONAL MICROIRRIGATION CONGRESS, 5., 1995, St. Joseph. Proccedings...St. Joseph: ASAE, 1995. p.269-274.

HAO, A. et al. Estimation of wet bulb formation in various soil during drip irrigation. Journal of the Faculty of Agriculture, Kyushu University, v. 01, n. 52, p. 187-193, 2007.

HASSUDA, S. Modelagem matemática: elaboração do modelo conceitual. Informática em Águas Subterrâneas. Informativo da Sociedade Brasileira de Águas Subterrâneas, n.10, p.2-3, março, 2000. 
HEERMANN, D. F.; KOHL, R. A. Fluid dynamics of sprinkler systems. In: JENSEN, M. E. Design and operation of farm irrigation systems. St. Joseph: American Society of Agricultural Engineers, 1983. P. 583-618.

HILLEL, D. Fundamentals of soil physics. Academic Press, Orlando, 1980.

HOWELL, T. A. Irrigation role in enchancing water use efficienty. In: National Irrigation Symposium. American Society os Agricultural Engineers, Phoenix, Arizona, 2000. p.66-80.

JACINTO, L. U. A pecuária do futuro com a ajuda da irrigação. Irrigação e Tecnologia Moderna. Brasília, n. 51, p. 50-54, 2001.

JADOSKI, S. O., et al. Manejo da irrigação para maximização do rendimento de grãos do Feijoeiro. Irriga, Botucatu, v. 8, n. 1, p. 1-9, jan-abr, 2003.

KELLER, J. Sprinkler and trickle irrigation. Logan: Utah State University, 1984, 281p.

KELLER, J.; BLIESNER, R. D. Sprinkle and trinkle irrigation. New York: Van Nostrand Reinhold, 1990. 652 p.

LI, J.; ZHANG, J.; RAO, M. Wetting patterns and nitrogen distributions as affected by fertigation strategies from a surface point source. Agricultural Water Management, v. 67, n. 02, p.89-104, 2004.

LIER, Q. J.; LIBARDI, P. L. Variabilidade dos parâmetros da equação que relaciona a condutividade hidráulica com a umidade do solo no método do perfil instantâneo. Revista Brasileira da Ciência do Solo, 23:1005-1014, 1999. Disponível em: <http://sbcs.solos.ufv.br/solos/revistas/v23n4a28.pdf> Acesso em: 17 de novembro de 2013.

LOIOLA, M. L.; SOUZA, F. Estatísticas sobre irrigação no Brasil segundo o Censo Agropecuário 1995-1996. Revista Brasileira de Engenharia Agrícola e Ambiental, Campina Grande, v. 5, n. 1, p. 171-180, 2001.

MILLER, R. J.; LOW, P. F. Threshold gradient for water flow in clay systems. Soil Science Society of America Journal, v.27, p.605-609, 1963.

MESQUITA, M. G. B. F; MORAES, S. O. A dependência entre a condutividade hidráulica saturada e atributos físicos do solo. Ciência Rural, Santa Maria, v.34, n.3, p.963-969, mai-jun, 2004.

MOSCA, M. A.; TESTEZLAF, R.; GOMES, E. P. DESENVOLVIMENTO DE EMISSORES ALTERNATIVOS PARA IRRIGAÇÃO SUBSUPERFICIAL DE BAIXA PRESSÃO. Irriga, Botucatu, v. 10, n. 3, p. 249-262, agosto-outubro, 2005.

NOGUEIRA, L. C. et al. Gotejamento Subterrâneo: Uma alternativa para a exploração agrícola dos solos dos tabuleiros costeiros. Empresa Brasileira de Pesquisa Agropecuária - EMBRAPA, 1997.

OLIVEIRA, A. S. de, et al. Avaliação do desempenho de sistemas pivô central na região Oeste da Bahia. Irriga, Botucatu, v. 9, n. 2, p. 126-135, maio - agosto de 2004. Disponível em: $<$ http://www.ufrb.edu.br/neas/images/Artigos_NEAS/2004_5.pdf> Acesso em: 15 de novembro de 2013. 
ORON, G.; DEMALACH, J.; HOFFMAN, Z.; CIBOTARU, R. Subsurface microirrigation with effluent. Journal of Irrigation and Drainage Engineering, Reston, v.117, n.1, p.25-37, 1991.

PAULINO, J.; FOLEGATTI, M.V.; ZOLIN, C.A.; SANCHEZ-ROMAN, R.M.; JOSE, J.V. Situacao da agricultura irrigada no Brasil de acordo com o censo agropecuario 2006. Irriga, Botucatu, v. 16, n. 2, p. 163-176, 2011.

PAVERO, J. Subsurface drip irrigation: Is it a good choice for your operation? Published by University of Nebraska and the U.S. Department of Agriculture, 2002. Disponível em: <http://cropwatch.unl.edu/archives/2002/crop02-8.htm\#top>. Acesso em 20 jan. 2013.

PAZ, et al. Recursos Hídricos, Agricultura Irrigada e Meio Ambiente. Revista Brasileira de Engenharia Agrícola e Ambiental, v.4, n.3, p.465-473. Campina Grande, PB, DEAg/UFPB, 2000. Disponível em: <http://www.scielo.br/pdf/\%0D/rbeaa/v4n3/v4n3a25.pdf>

PEREIRA, S. et al. Reflectometria no domínio do tempo na determinação do conteúdo de água no solo. Revista Brasileira de Engenharia Agrícola e Ambiental, v.10, n.2, p.306-314, Campina Grande - PB, 2006. Acesso em: 12 de jun. de 2013. Disponível em: <http://www.scielo.br/pdf/\%0D/rbeaa/v10n2/v10n2a09.pdf>

PHENE, C. J. et al. Advantages of subsurface irrigation for processing tomatoes. Acta Horticulturae, Wageningen, v.200, p.101-114, 1987.

PHENE, C.J., RUSKIN, R. Potential of subsurface drip irrigation for management of nitrate in wasterwater. In: INTERNATIONAL MICROIRRIGATION CONGRESS, 5., 1995, Orlando. Proceedings...st. Joseph: American Society of Agricultural Engineers, 1995. p.155-67.

PREVEDELLO, C. L. Física do solo com problemas resolvidos. Curitiba: Sociedade Autônoma de Estudos Avançados em Física do Solo. 1999, 446p.

REICHARDT, K. A água em sistemas agrícolas. São Paulo : Manole, 1990. 188p.

REINERT, D.J., REICHERT, J.M.; SILVA, V.R. Propriedades físicas de solos em sistema de plantio direto irrigado. In: CARLESSO, R.; PETRY, M.T.; ROSA, G.M. \& CERETTA, C.A. eds. Irrigação por aspersão no Rio Grande do Sul. Santa Maria, RS, 2001, 165p.

ROMERO, P., BOTIA, P., GARCIA, F. Effects regulated deficit irrigation under subsurface drip irrigation conditions on water relations of mature almond trees. Plant Soil 260, 155-168, 2004.

RUDOLPH, D. L. \& KACHANOSKI, R. G. Infiltration and solute transport experiments in unsaturated sand and gravel: experimental design and overview of results. Water Resources Research, v. 32, n. 3, p.519-532, 1996.

SAXTON, K. E.; RAWLS, W. J.; ROMBERGER, J. S.; PAPENDICK, R. I. Estimating generalized soil-water characteristics from texture. Soil Science Society of America Journal, v.50, p.1031-1036, 1986.

SKIERUCHA, W.; WILCZEK, A.; A FDR Sensor for Measuring Complex Soil Dielectric Permittivity in the 10-500 MHz Frequency Range. Sensors, v. 10, p. 3314-3329, 2010. 
SCHWARTZMASS. M.; ZUR, B. Emitter spacing and geometry of wetted soil volume. Journal of Irrigation and Drainage Engineering.. v.3, p.242-253, 1985. (Paper ASCE 112).

SILVA, C. R. da; ANDRADE JÚNIOR, A.S. de; SOUZA, C. F. Aspectos práticos na utilização da técnica de capacitância: desafios e aprendizagem. In: II Workshop de Aplicações de Técnicas Eletromagnéticas para o Monitoramento Ambiental. Anais...Taubaté-SP, 2008.

SIMUNEK, J., VAN GENUCHTEN, M.TH., SEJNA, M., 2008. Development and applications of the HYDRUS and STANMOD software packages, and related codes. Vadose Zone J. 7 (2), 587-600, doi:10.2136/VZJ2007.0077 (Special Issue "Vadose Zone Modeling").

SKAGGS, T.H., T.J. TROUT, J. SIMUNEK, AND P.J. SHOUSE. 2004. Comparison of HYDRUS-2D simulations of drip irrigation with experimental observations. J. Irrig. Drain. Eng. 130:304-310.

SOLOMON, K. H. Global uniformity of trickle irrigation system. Transactions of the ASAE, v.28, n.4, p.1151-1158, 1985.

SOUZA, C.F.; MATSURA, E.E.; FOLEGATTI, M.V.; COELHO, E.F.; OR, D. Sondas de TDR para a estimativa da umidade e da condutividade eletrica do solo. Irriga, Botucatu, v.11,n.1, p.12-25, 2006.

SOUZA, R. O. R. M. IRRIGAÇÃO E DRENAGEM. Material didático. UNIVERSIDADE FEDERAL RURAL DA AMAZÔNIA - INSTITUTO DE CIÊNCIAS AGRÁRIAS - ICA. Belém - PA, março, 2010. Disponível em: < http://www.portal.ufra.edu.br/attachments/803_resumo_geral_irrigacao.pdf> Acesso em: 15 de novembro de 2013.

SCHWARTZMAN, M.; ZUR, B. Emitter spacing and geometry of wetted soil volume. Journal of irrigation and drainage engineering, v. 112, n. 3, p. 242-253, 1986.

TELLES, D. D. Irrigação localizada. Item Irrigação e Tecnologia Moderna, n.23, p.29-30, 1985.

TESTEZLAF, R. FA876 . técnicas de irrigação. irrigação: técnicas, usos e impactos. Unicamp, 2002. 1 CD-ROM (notas de aula).

WALKER, W. R. Guidelines for designing and evaluating surface irrigation systems, Rome: FAO, 1989, 138p. (FAO. Irrigation and Drainage. Paper 45).

WU, I.P.; GITLIN, H.M. Drip irrigation application efficiency and schedules. Transactions of the ASAE, St. Joseph, v.26, p.92-99, 1983. 